\title{
MÉTODO PARA AVALIAÇÃO DA CONDUTA VISUAL DE LACTENTES
}

\author{
Heloisa G.R. Gardon Gagliardo1; Vanda M. Gimenes Gonçalves²; \\ Maria Cecília Marconi Pinheiro Lima ${ }^{3}$
}

\begin{abstract}
RESUM 0 - 0 objetivo deste estudo é apresentar um método para avaliação de funções visuais em lactentes no primeiro trimestre de vida. Utilizou-se o Roteiro de Avaliação da Conduta Visual em Lactentes, modificado de Gagliardo (1997). 0 material foi aro suspenso por cordão. Realizou-se estudo piloto com 33 lactentes, segundo os critérios de inclusão: neonatos assintomáticos, sem necessidade de cuidados especiais nas primeiras 48 horas; idade cronológica variando entre 1 e 3 meses; avaliação mensal sem nenhuma falta; procedência da região de Campinas/SP. No 10 mês destacaram-se as provas: fixação visual-93,9\%; contato de olho$90,9 \%$; seguimento visual horizontal-72,7\% e exploração visual do ambiente-97,0\% . No 3ำ mês: exploração visual da mão-42,4\% e aumento da movimentação de braços-36,4\%. Este Roteiro permitiu observar a função visual segundo a idade cronológica; desvio dessa função possibilitará pronto encaminhamento a serviços médicos para diagnóstico.
\end{abstract}

PALAVRAS-CHAVE: lactente, desenvolvimento visual função visual.

\begin{abstract}
A method to evaluate visual ability in infants
ABSTRACT - The purpose of this study is to introduce a method to evaluate visual functions in infants in the first three months of life. An adaptation of the Guide for the Assessment of Visual Ability in Infants (Gagliardo, 1997) was used. The instrument was a ring with string. It was implemented a pilot study with 33 infants, selected according to the following criteria: neonates well enough to go home within two days of birth; 1 to 3 months of chronological age; monthly evaluation with no absence; subjects living in Campinas/SP metropolitan area. In the first month we observed: visual fixation (93,9\%); eye contact (90,9\%); horizontal tracking $(72,7 \%)$; inspects surroundings $(97,0 \%)$. In the third month, we observed: inspects own hands $(42,4 \%)$ and increased movements of arms $(36,4 \%)$. This method allowed the evaluation of visual functions in infants, according to the chronological age. Alterations in this function will facilitate immediate referral to medical services for diagnoses.
\end{abstract}

KEY WORDS: infant, visual development, visual function.

0 desenvolvimento da visão, assim como o desenvolvimento de outras funções do organismo é permeado por fatores de maturação neurológica e por fatores de aprendizagem. É determinado por fatores genéticos e influenciado por fatores ambientais. A visão é 0 agente motivador das primeiras ações voluntárias dos membros superiores. Assim, um objeto, ao ser observado pela criança, desperta seu interesse e o desejo de tocá-lo. A criança então leva sua mão até 0 objeto e 0 agarra. Ao agarrá-lo, a criança 0 aproxima dos olhos para explorá-101. Dessa forma, espontaneamente, a criança estimula sua visão e aprimora habilidades manuais. Olhando, a criança envia estímulos para a retina, vias ópticas e córtex visual. Esses estímulos fazem com que essas estruturas desenvolvam seus contatos celulares e sinapses sejam realizadas pelas células neurais, favorecendo a função visual e tornando-a permanente ${ }^{2-}$ ${ }^{4}$. Sabe-se que há inter-relação entre maturação neurológica e experiências ambientais: uma favorece 0 desenvolvimento da outra. Exemplo disso é o que ocorre na esfera do desenvolvimento visuocortical, podendo o enriquecimento das experiências visuais pelo estímulo ambiental alterar a maturação. As modificações maturacionais ocorridas podem, por sua vez, alterar a prontidão do organismo para assimilar os estímulos ambientais ${ }^{5}$.

Os clássicos estudos experimentais de Hubel e Wiesel

Centro de Estudos e Pesquisas em Reabilitação "Prof. Dr. Gabriel Porto"; Departamento de Neurologia e Centro de Investigação em Pediatria da Faculdade de Ciências M édicas/Universidade Estadual de Campinas (UNICAM P), Campinas SP, Brasil: ' ${ }^{1}$ Doutora em Ciências Médicas, Terapeuta Ocupacional; ${ }^{2}$ Professora Assistente Doutora, Neurologista Infantil; 'ंDoutora em Ciências M édicas, Fonoaudióloga: Apoio: Fundação de Amparo à Pesquisa do Estado de São Paulo (FAPESP), Fundo de Apoio à Pesquisa (FAEP/Unicamp).

Recebido 18 Outubro 2001, recebido na forma final 29 Setembro 2003. Aceito 6 Novembro 2003.

Dra. Heloisa Gagliardo - Rua Tessália Vieira de Camargo 126 - 13084-971 Campinas SP - Brasil. E-mail: heloisa@fcm.unicamp.br 
realizados por volta da década de sessenta ${ }^{6}$, comprovaram que a privação do estímulo visual nas primeiras semanas de vida provocava a perda da capacidade visual e alterações anatômicas nas vias neurológicas da visão. Estes estudos abriram novas perspectivas para a investigação da plasticidade cerebral e dos períodos críticos para o desenvolvimento em diferentes regiões do sistema nervoso central (SNC). Assim, nos últimos anos, as pesquisas têm se voltado para a observação dos períodos críticos para a aquisição de habilidades durante o desenvolvimento. Considera-se o período crítico como o tempo durante o qual o desenvolvimento é particularmente sensível a condições externas nocivas ${ }^{7}$. A estrutura anatômica básica das vias visuais inicia-se no período pré-natal e a sinaptogênese tem início na 28a semana de idade gestacional. Ao nascimento, apenas $10 \%$ das sinapses estão presentes; esse período se relaciona com baixo alerta visual e com o início da fixação visual ${ }^{8}$. A densidade sináptica aumenta rapidamente desde 0 nascimento até o quarto mês de vida, repercutindo na melhora do alerta visual, na fixação e na coordenação do seguimento visual. Atinge o máximo da sinaptogênese aos oito meses de vida pós-natal, quando se iniciam fenômenos regressivos, caracterizados por morte celular programada geneticamente e a eliminação seletiva de processos neuronais e de sinapses. $\mathrm{Na}$ idade de onze meses, aproximadamente $40 \%$ das sinapses foram eliminadas ${ }^{9}$. Os eventos regressivos no desenvolvimento do cérebro são reconhecidos como altamente críticos, sendo de grande importância a eliminação sináptica na plasticidade do SNC em desenvolvimento bem como o efeito potencial de experiências ambientais na função neural. A observação de morte celular e eliminação de processos neuronais e de sinapses, ocorrendo durante o período de organização neuronal, tem implicações para demonstrar que a plasticidade do cérebro em desenvolvimento diminui após esse período ${ }^{10}$.

Vários fatores interferem na plasticidade do SNC, entre eles o fator de reconhecimento molecular, os mecanismos baseados na cooperação e competição entre os neurônios e a atividade das fibras aferentes a partir da estimulação ambiental durante um período crítico. Outro fator refere-se aos ajustes finos entre as sinapses que são formadas nos estágios precoces do desenvolvimento.Após o período crítico, as conexões sinápticas existentes tornam-se estáveis e muito menos susceptíveis às mudanças ${ }^{11,12}$. Essas modificações anatômicas repercutem na observação clínica: é no primeiro ano de vida que ocorrem as maiores e mais notáveis transformações que há de sofrer 0 organismo, com saltos evolutivos ocorrendo nos menores períodos de tempo ${ }^{13,14}$.

Com base nesses conceitos, verifica-se a importância do primeiro ano de vida para o desenvolvimento da criança e a importância da detecção de alterações no seu desenvolvimento, para que mais cedo seja feito o diagnóstico e iniciada a possível intervenção. Neste sentido, têm sido utilizadas com maior freqüência triagens clínicas em crianças consideradas de risco ${ }^{15}$. Porém, a detecção em todas as situações, de risco ou não, é o principal veículo para a intervenção precoce. Esta proposta não pretende realizar diagnóstico, mas detectar possíveis alterações que sirvam de alerta para a observação mais cuidadosa e encaminhamento a serviços médicos para diagnóstico. Caracteriza-se, portanto, como um procedimento de prevenção secundária16,17.

\section{MÉTODO}

Trata-se de estudo de coorte longitudinal. A população foi constituída por neonatos procedentes de 5 hospitais maternidade de Campinas/SP, após aprovação do projeto de pesquisa pelas Comissões de Pesquisa e de Ética da Universidade Estadual de Campinas (UNICAM P) e dos Diretores Clínicos ou de Comissões de Ética dos hospitais participantes. Entre os meses de Maio e Julho de 1994, em 7 dias sorteados, no período de 24 horas, foram considerados todos os recém-nascidos, num total de 281 sujeitos. Por meio de consulta ao prontuário materno e do recém-nascido, cartão de pré-natal e entrevista com mãe, preencheu-se o Roteiro deAnamnese, previamente elaborado, para levantamento de indicadores de risco para lesão neurológica.

Foram convidados 178 recém-nascidos neonatos assintomáticos, sem necessidade de cuidados especiais nas primeiras 48 horas que preencheram os critérios de inclusão: idade gestacional entre 37 e 42 semanas e o peso ao nascimento entre 2500 e 4000 gramas $^{18}$; índice de Apgar $>7$ nos $1^{\circ}$ e $5^{\circ}$ minutos; sem intercorrências gestacionais ou neonatais; procedentes da região delimitada pelo Diretório Regional de Saúde XII (DIR-XII) e cujos pais assinaram o Termo de Consentimento Livre e Esclarecido. Dos 178 recém-nascidos selecionados, retornaram espontaneamente para avaliação mensal 62 lactentes no primeiro mês, 54 no segundo e 54 no terceiro mês. Entre esses, os ausentes eram convocados por telegrama pré-taxado e telefonemas.

Para o presente estudo foi considerada a amostra de coorte longitudinal de 33 lactentes normais, que não apresentaram faltas nas avaliações mensais do primeiro trimestre de vida. Foram do sexo feminino 16 lactentes e do sexo masculino 17.

A avaliação mensal no primeiro trimestre de vida foi realizada no período compreendido entre a data de aniversário e o intervalo de mais ou menos 7 dias, no Laboratório de Estudos do Desenvolvimento Infantil-I (LEDI-I), no Centro de Estudos e Pesquisa em Reabilitação Gabriel Porto (CEPRE).

Para a elaboração do Roteiro de Avaliação da Conduta Visual de Lactentes, selecionaram-se 9 provas (Quadro 1) do Roteiro de Avaliação do Comportamento Visuomotor do Lactente ${ }^{1}$, elaborado a partir da adaptação de provas do Roteiro de Avaliação Neurológica do Recém-nascido ${ }^{17}$ e das Escalas Bayley de Desenvolvimento Infantil ${ }^{19}$ (BSID-II). 0 instrumental utilizado foi aro suspenso por cordão e face do examinador.

Os procedimentos para a aplicação do Roteiro de Avaliação da Conduta Visual de Lactentes foram os seguintes:

Prova 1 - Fixação Visual. Posição da criança - supino. Posição do examinador - atrás da criança, fora do seu campo de visão. Instrumento/estímulo - aro suspenso por cordão. Aplicação - suspenda 0 aro pelo cordão, até que a extremidade inferior esteja na linha média da criança, aproximadamente 20 a $30 \mathrm{~cm}$ acima dos seus olhos. Mova 
Quadro 1. Roteiro de avaliação da conduta visual de lactentes.

Nome
Data Nasc.
-

0 aro suavemente para atrair 0 olhar da criança e então o segure parado na linha média. Realize no máximo três tentativas. Resposta - olhar para 0 aro pelo menos por três segundos.

Prova 2 - Contato de olho com o examinador. Posição da criança - supino. Posição do examinador - de frente para a criança, com alinhamento face a face. Instrumento/estímulo - rosto do examinador. Aplicação - inclinar-se até que sua face esteja $30 \mathrm{~cm}$ acima e alinhada com a face da criança. Sorria e acene com a cabeça quatro ou cinco vezes. Realize até três tentativas. Resposta - olhar para o examinador pelo menos por três segundos.

Prova 3 - Sorriso como resposta ao contato social. Posição da criança - supino. Posição do examinador - de frente para a criança, com alinhamento face a face. Instrumento/estímulo - rosto do examinador. Aplicação - inclinar-se até que sua face esteja $30 \mathrm{~cm}$ acima e alinhada com a face da criança. Sorria e acene com a cabeça quatro ou cinco vezes; observe a resposta e em seguida fale suavemente com a criança. Realize até três tentativas. Resposta - sorrir ou vocalizar em resposta a qualquer dos estímulos.

Prova 4 - Sinergia oculocefalógira - Seguimento visual horizontal. Posição da criança - supino. Posição do examinador - atrás da criança, fora do seu campo de visão. Instrumento/estímulo - aro suspenso por cordão. Aplicação - suspenda o aro pelo cordão, até que a extremidade inferior esteja na linha média da criança, aproximadamente 20 a $30 \mathrm{~cm}$ acima dos seus olhos. Atraia o olhar da criança para 0 aro e lentamente movimente-o (a cada 3 a 4 segundos percorrendo $30 \mathrm{~cm}$ ) para a direita e para a esquerda e então para a linha média novamente (isto constitui uma excursão). Se o olhar da criança deixar 0 aro, atraia-o novamente antes de completar a excursão. A presente um máximo de três excursões. Resposta - acompanhar com os olhos a trajetória do aro em uma excursão completa, mesmo se 0 olhar da criança abandonar 0 aro uma ou duas vezes.

Prova 5 - Sinergia oculocefalógira - Seguimento visual vertical. Posição da criança - supino. Posição do examinador - atrás da criança, fora do seu campo de visão. Instrumento/estímulo - aro suspenso por cordão. Aplicação - suspenda o aro pelo cordão, até que a extremidade inferior esteja na linha média da criança, aproximadamente 20 a $30 \mathrm{~cm}$ acima dos seus olhos. Atraia 0 olhar da criança para 0 aro e lentamente movimente-o (a cada 3 a 4 segundos percorrendo 30 $\mathrm{cm}$ ) para cima e para baixo e então para a linha média novamente (isto constitui uma excursão). Se o olhar da criança deixar o aro, atraiao novamente antes de completar a excursão. Apresente um máximo de três excursões. Resposta - acompanhar com os olhos a trajetória do aro em uma excursão completa, mesmo se o olhar da criança abandonar 0 aro uma ou duas vezes.

Prova 6 - Exploração visual do ambiente. Durante o exame, observe o comportamento visual exploratório do lactente, quando ele estiver livre para seguir seu próprio interesse. Resposta - exploração visual espontânea do ambiente.

Prova 7 - Exploração visual da mão. Durante o exame, observe o comportamento do lactente enquanto ele estiver livre para seguir seu próprio interesse. Esta prova se faz durante períodos de repouso do lactente, calmo e desperto, sem nenhum estímulo. Resposta - olhar espontaneamente para as mãos.

Prova 8 - Aumento da movimentação de membros superiores ao visualizar o objeto. Posição da criança - supino ou sentada. Posição do examinador - de frente para a criança. Instrumento/estímulo - aro suspenso por cordão. Aplicação - suspenda o aro pelo cordão, até que a extremidade inferior esteja na linha média da criança, aproximadamente 20 a $30 \mathrm{~cm}$ acima dos seus olhos. Mova 0 aro suavemente para atrair 0 olhar da criança e então o segure parado na linha média. Realize no máximo três tentativas. Resposta aumentar a movimentação de membros superiores enquanto estiver em contato visual com o objeto.

Prova 9 - Estender o braço na direção do objeto visualizado. Posição da criança-supino ou sentada. Posição do examinador - de frente para a criança. Instrumento/estímulo - aro suspenso por cordão. Aplicação - suspenda 0 aro pelo cordão, até que a extremidade inferior esteja na linha média da criança, aproximadamente 20 a 30 $\mathrm{cm}$ acima de seus olhos. Mova 0 aro suavemente para atrair 0 olhar da criança e então o segure parado na linha média. Realize no máximo três tentativas. Resposta - mover os membros superiores propositadamente em direção ao aro enquanto olha para ele.

Utilizou-se 0 banco de dados do programa computacional EPIINFO $6.02^{20}$ e a análise estatística foi pela prova " Q" de Cochran ${ }^{21}$, 
para a comparação dos três meses e dois a dois. 0 valor de " $Q$ " tabelado correspondeu a 3,84; qualquer valor de " $Q$ " superior a 3,84 foi equivalente a $p<0,05$. 0 nível de significância foi de 0,05.

\section{RESULTADOS}

0 presente estudo compreende um grupo de 33 lactentes avaliados mensalmente no primeiro trimestre de vida. $A$ distribuição das freqüências de respostas encontra-se na Tabela 1. Observou-se que a maioria das provas foi executada a partir do primeiro mês de vida, com exceção das provas de aumento da movimentação de membros superiores ao visualizar objetos e estender o braço em direção ao objeto visualizado, que se iniciaram respectivamente no segundo e terceiro meses.

Os resultados mostraram a capacidade de alerta visual dos lactentes desde o primeiro mês de vida, possibilitando alta freqüência de respostas (mais de $90 \%$ dos lactentes) nas provas de fixação visual de objetos, contato de olho com examinador e exploração visual espontânea do ambiente. $\mathrm{Na}$ avaliação longitudinal, não houve diferença significativa na comparação dessas provas nos três meses, conforme demonstrado na Tabela 2.

0 seguimento visual horizontal avaliado pelo sinergia óculo-cefalógira utilizando 0 aro suspenso, foi observado com a mesma freqüência no primeiro e segundo meses; entretanto houve diferença significativa entre o segundo e terceiro meses, com diminuição do seguimento visual horizontal no terceiro mês.

O seguimento visual vertical mostrou diferença significativa entre o primeiro e segundo meses, havendo maior freqüência de respostas no segundo mês; houve diferença significativa entre o segundo e terceiro meses, ocorrendo menor freqüência de respostas no terceiro mês. Concluindo, entre o segundo e terceiro e meses de vida, tanto o seguimento horizontal como o vertical mostraram diminuição de respostas com diferença estatisticamente significativa. Outras provas do Roteiro de Avaliação da Conduta Visual de Lactentes demonstraram diferença significativa comparando os meses dois a dois, conforme demonstrado na Tabela 3.

\section{DISCUSSÃO}

Observou-se desde o primeiro mês de vida a capacidade de fixação visual na linha média de objetos, do rosto do examinador e a exploração espontânea do ambiente, sem diferença em relação ao segundo e ao terceiro meses. 0 seguimento visual horizontal e vertical mostrou aumento de frequência do primeiro para o segundo mês entretanto a diferença foi significativa apenas no seguimento visual vertical. É plausível estabelecer um paralelo entre as manifestações clínicas, as modificações anatômicas no córtex visual e a desenvolvimento funcional. Relativamente poucas conexões sinápticas são encontradas à época do nascimento, verificandose 0 alerta visual para as funções de fixação na linha média; estão apenas se iniciando as funções de seguimento visual. 0 rápido aumento que ocorre na sinaptogênese até a idade de quatro meses correlaciona-se com o rápido aumento do alerta visual e do seguimento visual neste período ${ }^{8}$.

As funções oculomotoras são referidas como pré-requisito para a habilidade da criança trazer o olhar para os objetos de seu interesse ${ }^{3}$. Essas funções têm valor clínico e devem ser avaliadas desde muito cedo. 0 desvio nessas funções impõe a detecção precoce de alterações visuais ou neurológicas ou ainda de outros transtornos do desenvolvimento, incluindo a Síndrome do Autismo Infantil. Analisando filmagens pregressas, foram observadas, entre outras manifestações, a dificuldade em estabelecer contato visual face-a-face no pri-

Tabela 1. Distribuição das freqüências de respostas nos três meses.

\begin{tabular}{lccc}
\hline & & $\mathrm{N}=33$ \\
Provas & \begin{tabular}{c} 
10 mês \\
\cline { 2 - 3 }
\end{tabular} & $\begin{array}{c}20 \text { mês } \\
(\%)\end{array}$ & $(\%)$ mês \\
\hline Fixação visual & 93,9 & 100 & 100 \\
Contato de olho com o examinador & 90,9 & 97,0 & 97,0 \\
Sorriso como resposta ao contato social & 33,3 & 75,8 & 75,8 \\
Sinergia óculo-cefalógira-Seguimento visual horizontal & 72,7 & 84,8 & 33,3 \\
Sinergia óculo-cefalógira-Seguimento visual vertical & 51,3 & 81,8 & 36,4 \\
Exploração visual do ambiente & 97,0 & 100 & 100 \\
Exploração visual da mão & 3,0 & 3,0 \\
Aumento da movimentação de membros superiores & 0,0 & 42,4 \\
Estender o braço na direção do objeto visualizado & 0,0 & 36,1 \\
\hline
\end{tabular}


Tabela 2. Identificação das provas visuais que não apresentaram diferença nos três meses.

\begin{tabular}{lcc}
\hline Provas & $Q$ & $p$ \\
\hline Fixação visual & 4,00 & $>0,05$ \\
Contato de olho com o examinador & 2,00 & $>0,05$ \\
Exploração visual do ambiente & 2,00 & $>0,05$ \\
\hline
\end{tabular}

a Prova "Q" de Cochran

meiro ano de vida ${ }^{22,23}$. Foi valorizada a forma como o lactente estabeleceu 0 contato visual e 0 modo como focalizou 0 estímulo visual: foi observada com maior frequência a atividade de olhar 0 ambiente, com características de passividade da focalização visual, em detrimento da atividade de estabelecer contato visual com a mãe. Apesar da maioria dos sintomas relevantes envolverem comportamentos sociais e de comunicação que se desenvolverão posteriormente, as autoras ${ }^{22}$ apontaram esses sinais, apesar de limitados, como sugestivas de manifestações da Síndrome do Autismo Infantil no primeiro mês de vida.

Outras provas do Roteiro de Avaliação da Conduta Visual de Lactentes como 0 seguimento visual horizontal e vertical mostraram diferença significativa entre 0 segundo e terceiro meses, ocorrendo menor freqüência de respostas no terceiro mês. Conjecturou-se que esse resultado poderia ser atribuído ao desinteresse dos lactentes pelo estímulo apresentado. Eles se recusavam a fixar a visão no aro suspenso e demonstravam grande interesse em explorar o ambiente ou suas mãos ou a face do examinador. Esse fato pode ser considerado como previsível, em função da idade do lactente. Este comportamento corrobora 0 que é descrito em outros estudos ${ }^{19,24}$ no que se refere ao interesse dos lactentes por estímulos novos e mais complexos a partir do terceiro mês de vida. 0 aumento da interação ${ }^{24}$ se dá por volta dos dois meses de idade, em função do aumento significativo da exploração do ambiente.
Outras provas do Roteiro de Avaliação da Conduta Visual de Lactentes, como a exploração visual da mão e 0 aumento da movimentação dos braços ao visualizar objetos, foram observadas em pequeno número de lactentes no primeiro e segundo meses, havendo diferença significativa com o terceiro mês, sendo comportamento característico desta idade. 0 comportamento de estender a mão em direção ao objeto não foi observado no primeiro e segundo meses e teve início num pequeno número de lactentes no terceiro mês, havendo diferença significativa em relação aos meses anteriores. Esses resultados são relevantes, demonstrando a importância da visão para a aquisição de habilidades manuais, como agente motivador das ações dos membros superiores realizadas pelos lactentes.

Estes resultados estão de acordo com um estudo sobre 0 objeto visualizado tangível que verificou o comportamento de alcançar, ou seja, estender o braço em direção ao objeto visualizado, com inicio no terceiro mês de vida ${ }^{25}$. Os resultados não foram estatisticamente significativos devido ao baixo número de sujeitos avaliados na pesquisa. Entretanto, 0 autor concluiu que 0 desenvolvimento inicial da preensão em lactentes é motivado pela atenção para 0 alcance, que é predominantemente controlada pela visão.

Existe na literatura alguma divergência quanto à idade exata de aparecimento do alcance de objetos que são visualizados. Estudo realizado na década de 90 em neonatos com 17 dias de vida ${ }^{26}$ verificou 0 alcance voluntário para objetos visualizados, desde que utilizadas determinadas manobras de facilitação. Para a autora, esses resultados sugerem que funções corticais superiores existem desde as primeiras semanas de vida, mas estão ocultas pela atividade reflexa característica dessa idade.

\section{CONCLUSÕES}

Os resultados desse estudo demonstraram habilidade

Tabela 3. Identificação das provas visuais que apresentaram diferenças significativas comparando os meses dois a dois.

\begin{tabular}{lccc}
\hline Provas & $\begin{array}{c}10 \text { - 20 } \\
\text { meses }\end{array}$ & $\begin{array}{c}20 \text { - 30 } \\
\text { meses }\end{array}$ & $\begin{array}{c}10 \text { - 30 } \\
\text { meses }\end{array}$ \\
\hline Sorriso como resposta ao contato social & $14,0^{*}$ & 0,89 & $4,17^{*}$ \\
Seguimento visual horizontal & 1,6 & $13,76^{*}$ & $8,89^{*}$ \\
Seguimento visual vertical & $8,07^{*}$ & $14,22^{*}$ & 1,47 \\
Exploração visual da mão & 0,0 & $13,0^{*}$ & $13,0^{*}$ \\
Aumento da movimentação de membros superiores & 3,0 & $7,36^{*}$ & $12,0^{*}$ \\
Estende braço na direção do objeto visualizado & 0,0 & $4,0 *$ & $4,0^{*}$ \\
\hline
\end{tabular}

a Prova "Q" de Cochran; * resultado estatisticamente significativo. 
visual na maioria dos lactentes no primeiro mês de vida, possibilitando a fixação visual, o contato de olho com 0 examinador e a exploração visual do ambiente. 0 seguimento visual horizontal foi mais frequente que o seguimento vertical no primeiro mês.

A exploração visual da mão e o aumento da movimentação de membros superiores ao visualizar objetos foram comportamentos característicos do terceiro mês, sendo observado num pequeno número de crianças no segundo mês. 0 comportamento de estender o braço em direção ao objeto foi observado a partir do terceiro mês.

0 Roteiro de Avaliação da Conduta Visual de Lactentes utilizou procedimentos simples, com material de baixo custo. Entretanto, o profissional deverá ser especialmente treinado em observar o comportamento visual e avaliar as respostas do lactente nessa faixa etária.

0 Roteiro de Avaliação da Conduta Visual de Lactentes é proposta para detectar, no primeiro trimestre de vida, alterações no comportamento visual. Os desvios servirão de alerta para o diagnóstico de alterações visuais bem como de outros transtornos do neurodesenvolvimento. 0 diagnóstico, ocorrendo nesta faixa etária, favorece, por sua vez, o pronto encaminhamento a serviços de habilitação infantil, obtendose melhores perspectivas na eficiência visual, no desenvolvimento futuro, e na qualidade de vida das crianças.

Agradecimentos - Ao Centro de Estudos e Pesquisa em Reabilitação "Gabriel Porto" (CEPRE), ao Departamento de Neurologia e ao Centro de Investigação em Pediatria (CIPED), todos da FCM/UNICAMP, pelo apoio. Ao Grupo Interdisciplinar de Avaliação do Desenvolvimento Infantil (GIADI).

\section{REFERÊNCIAS}

1. Gagliardo HGRG. Investigação do comportamento visuomotor do lactente normal no primeiro trimestre de vida. Dissertação de Mestrado Faculdade de Ciências Médicas da Universidade Estadual de Campinas, Campinas, 1997.

2. Hyvärinen L. La visión normal y anormal en los niños. Madrid: Organización Nacional de Ciegos Españoles, 1988.

3. Hyvärinen L. Considerations in evaluation and treatment of the child with low vision. Am J Occup Ther 1995;59:891-897.

4. Alves MR, Kara-José N. O olho e a visão. Rio de Janeiro: Vozes, 1996.

5. Lipsitt LP. Learning in infancy: cognitive development in babies. J Pediatr 1986;109:172-182.

6. Hubel DH. Ojo, cerebro y visión. Murcia: Servicio de Publicaciones, Universidad de Murcia, 1999:191-219.

7. Kinney HC, Brody BA, Kloman AS, Gilles FH. Sequence of central nervous system myelination in human infancy. J Neurophatol Exp Neurol 1988;47:217-234.

8. Huttenlocher, PR. Morphometric study of human cerebral cortex. Dev Neuropsych 1990;28:517-527.

9. Pallagrosi, M. Neuroplasticity of the developing brain and child cortical visual impairment. Ann Int Super Sanit 1993;29:163-165.

10. Oppenheim RW. Cell death during development of the nervous system. Annu Rev Neurosc 1991;14:453-501.

11. Kandel ER, Schwartz JH, Jessell TM. Desenvolvimento do sistema nervoso. In Fundamentos da neurociência e do comportamento. Rio de Janeiro: Prentice-Hall, 1997:75-91.

12. Gazzaniga MS, Ivry RB, Mangun GR. Development and plasticity. In Cognitive Neuroscience: the biology of the mind. New York: WW Norton, 1998:465-493.

13. Costalat DM. Psicomotricidade. 7.Ed. Rio de Janeiro: Globo, 1987.
14. Diament AJ. Exame neurológico do lactente. In Diament AJ, Cypel S. (eds) Neurologia infantil. 3.Ed. São Paulo: Atheneu, 1996:35-62.

15. Baird AS, Hemming AM. Neonatal vision screening. J Vis Impairm Blind 1982;76:182-185.

16. Temporini ER, Kara-José N. Níveis de prevenção de problemas oftalmológicos: propostas de investigação. Arq Bras Oftalm 1995;58:189-192.

17. Dargassies SA. Desarrollo neurológico del recién nacido de termino y prematuro. Buenos Aires: Medica Panamericana, 1977.

18. Battaglia FC, Lubchenco LO. A practical classification of newborn infants by weight and gestational age. J Pediatr 1967;71:159-163.

19. Bayley N. Bayley scales on infant development. 2.Ed, San Francisco: American Psychological Corporation, 1993.

20. Dean AG, Dean JA, Coulombier P, et al. Epi info, version 6: a word processing, database, and statistics program for epidemiology on microcomputers. Atlanta: Centers for Disease Control and Prevention, 1994.

21. Fleiss JL. Statistical methods for rates and proportions. 2.Ed. New York: John Wiley \& Sons 1981.

22. Nogueira SE, Moura MLS. Diagnóstico precoce de autismo e desenvolvimento infantil inicial: um estudo comparativo de dois bebês com um mês de idade. Temas sobre Desenvolvimento 2000;53:17-24.

23. Osterling J, Dawson G. Early recognition of children with autism: a study of first birthday home videotapes. J Autism Develop Dis 1994;24:247-257.

24. Barraga NC. Sensory perceptual development. In Scholl GT (ed). Foundation of education for the blind and visually handicapped children and youth: theory and practice. New York: American Foundation for the Blind, 1986:85-98.

25. Field J. Coordination of vision and prehension in young infants. Child Dev 1977;48:97-103.

26. Amiel-Tison $\mathrm{C}$. Neurological assessment of the neonate revisited: a personal view. Dev Med Child Neurol 1990;32:1105-1113. 